\title{
Differences in Resting-state Quantitative Electroencephalography Patterns in Attention Deficit/Hyperactivity Disorder with or without Comorbid Symptoms
}

\author{
Jun Won Kim ${ }^{1}$, Soo Yeon $\mathrm{Kim}^{2}$, Jae-won $\mathrm{Choi}^{2}$, Kyoung Min $\mathrm{Kim}^{2}$, Sojeong Hannah Nam², Kyung Joon $\mathrm{Min}^{3}$, \\ Young Sik Lee ${ }^{3}$, Tae Young Choi $^{1}$ \\ ${ }^{1}$ Department of Psychiatry, Catholic University of Daegu School of Medicine, Daegu, ${ }^{2}$ Division of Child and Adolescent Psychiatry, Department \\ of Psychiatry, Seoul National University Hospital, Seoul, ${ }^{3}$ Department of Psychiatry, Chung-Ang University College of Medicine, Seoul, Korea
}

\begin{abstract}
Objective: The aim of the present study was to evaluate the role of comorbid psychiatric symptoms on quantitative electroencephalogram (QEEG) activities in boys with the attention deficit/hyperactivity disorder (ADHD).

Methods: All participants were male students in the second, third or fourth grade in elementary school. Therefore, there were no significant differences in age or sex. Participants with ADHD were assigned to one of three groups: pure $A D H D(n=22)$, $A D H D$ with depressive symptoms ( $n=11)$, or ADHD with problematic internet use $(n=19)$. The Korean version of the Children's Depression Inventory and the Korean Internet Addiction Self-scale were used to assess depressive symptoms and problematic internet use, respectively. Resting-state EEG during eyes closed was recorded, and the absolute power of five frequency bands was analyzed: delta (1-4 Hz), theta $(4-8 \mathrm{~Hz})$, alpha $(8-12 \mathrm{~Hz})$, beta $(12-30 \mathrm{~Hz})$, and gamma $(30-50 \mathrm{~Hz})$.

Results: The ADHD with problematic internet use group showed decreased absolute theta power at the central and posterior region compared with the pure ADHD group. However, The ADHD with depressive symptoms group showed no significant differences compared with the other groups.

Conclusion: These findings will contribute to a better understanding of brain-based electrophysiological changes in children with $\mathrm{ADHD}$ in accordance with comorbid psychiatric symptoms.
\end{abstract}

KEY WORDS: Electroencephalography; Attention deficit disorder with hyperactivity; Depression; Comorbidity.

\section{INTRODUCTION}

Attention deficit/hyperactivity disorder (ADHD) is one of the most common psychiatric disorders among children and adolescents. ${ }^{1)}$ ADHD symptoms in childhood and adolescence have negative consequences in multiple areas. Inattention or hyperactivity/impulsivity may cause significant impairment in academic, social, emotional, and familial functioning. ${ }^{2)}$ ADHD is associated not only with inattention and/or hyperactivity-impulsivity, which is the main symptom, but also with secondary symptoms, such as learning disabilities, ${ }^{3)}$ anxiety, ${ }^{4)}$ depression, ${ }^{5)}$ and conduct disorder (CD). ${ }^{6}$ These symptoms lead children to experience personal disadvantages at school, ${ }^{7)}$ and these

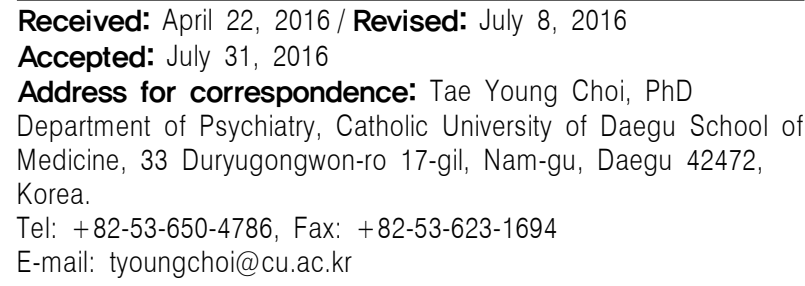

individuals may also experience various socioeconomic problems when they become adults. ${ }^{8,9)}$

From a clinical perspective, there are two reasons for focusing on comorbidity or comorbid psychiatric symptoms in children with ADHD. First, it is not common to encounter children with ADHD who have only "pure" ADHD symptoms. According to a previous study, more than $50 \%$ of children with ADHD have other psychiatric disorders. ${ }^{10)}$ Second, the existence of comorbid disorders with ADHD can influence medication effects, side effects and disease progression. When ADHD is comorbid with depression or anxiety, the response to stimulants, such as methylphenidate, is lower than when there is no comorbid disorder. ${ }^{11)}$ Among other various comorbid symptoms, this study has specifically focused on depressive symptoms, which may affect electroencephalogram (EEG), ${ }^{12)}$ and problematic internet use, which shows high comorbidity, particularly in Korea ${ }^{13)}$ Oppositional defiant disorder (ODD), the most common comorbid disorder of ADHD, is excluded from this study because an existing study has demonstrated that ODD does not significantly

(c) This is an Open-Access article distributed under the terms of the Creative Commons Attribution Non-Commercial License (http://creativecommons.org/licenses/by-nc/4.0) which permits unrestricted non-commercial use, distribution, and reproduction in any medium, provided the original work is properly cited. 
affect EEG results. $^{14)}$

Generally, it is common for depressive disorder to occur several years after the onset of ADHD. ${ }^{15)}$ According to a prospective 4-year follow-up study conducted with children with ADHD, the prevalence of comorbid depressive disorder was $29 \%$ at the initial assessment, and this increased to $45 \%$ after 4 years. ${ }^{7)}$ When these two disorders coexist, psychiatric symptoms become more severe over time, and the risk of functional impairment increases in the long term. ${ }^{16)}$ Therefore, it is important to assess whether children with ADHD have depressive symptoms initially. Additionally, a correlation between ADHD and internet addiction, which is a behavioral addiction, was previously verified by a study conducted with schoolaged children. ${ }^{13)}$ Adolescents exhibit more ADHD as they spend more time on a console or internet video games, ${ }^{17}$ ) and this correlation was also observed in adults. ${ }^{18)}$ In Korea, problematic internet use or internet addiction is more prevalent than in any other country because of the advanced internet environment. ${ }^{19)}$ The existence of ADHD symptoms is one important risk factor among various factors contributing to internet addiction. ${ }^{13)}$

In ADHD studies, findings related to resting-state quantitative electroencephalogram (QEEG) have been relatively consistent over a long period of time. ${ }^{20)}$ The most consistently reported EEG findings in children with ADHD are increased theta power or an elevated proportion of slow to fast frequency power and theta/beta ratio compared with typically developing children. ${ }^{12,21,22)}$ Increased slow frequency and decreased fast frequency activities are usually interpreted as the hypo-arousal model of ADHD. However, the results of QEEG studies are not always consistent. In a recent study, $60 \%$ of children with ADHD showed increased theta activity, and $40 \%$ exhibited decreased theta activity. ${ }^{23)}$ Fast frequency activity, such as beta, showed even more mixed results. Some studies have reported decreased beta power, ${ }^{22,24)}$ whereas others have reported increased beta power ${ }^{25)}$ or the absence of a group difference in beta power. ${ }^{26)}$ Such mixed results have also been reported for the alpha frequency. ${ }^{22,23,27)}$ This inconsistency between studies may be caused by several factors; most importantly, various participant characteristics and circumstances during EEG recording, such as whether participants had their eyes open or closed, have been shown to influence the results. ${ }^{28)}$ Another important influential factor is a lack of consideration of other comorbid psychiatric conditions. ${ }^{12)}$

One study has explored whether QEEG activity in children with ADHD is influenced by psychiatric comorbid- ities, such as disruptive behavior disorders and depression. The authors reported that psychiatric comorbidities exert significant mediation effects on the theta-to-beta ratio. ${ }^{12)}$ To our knowledge, no study has investigated resting-state QEEG activities in children with ADHD with comorbid psychiatric symptoms, such as depressive symptoms and problematic internet use. In this context, the aim of the present study was to evaluate the role of comorbid psychiatric symptoms on QEEG activities. We hypothesized that the resting-state QEEG activities in boys with ADHD would differ from those of boys with ADHD with depressive symptoms or problematic internet use.

\section{METHODS}

\section{Subjects}

The subjects were elementary school students who participated in the "Touch Brain Attention Enhancement Camp" sponsored by Gongju National Hospital from 2011 to 2013. Written consent for the medical use of the test results was received from all of the participants' guardians, and the Gongju National Hospital Clinical Research Ethics Committee approved the content and the ethical conduct of this study (2013-04). ADHD diagnosis was based on the Korean version of the Diagnostic Interview Schedule for Children Version IV (DISC-IV), which is a structured interview tool. A definitive diagnosis of ADHD was confirmed by multiple child and adolescent psychiatrists. Exclusion criteria for all subjects were a history of significant head injury, neurological disorder, genetic disorder, substance dependence, epilepsy or psychotic disorder. Children who exhibited an intelligence quotient of 70 or lower according to the Korean-Wechsler Intelligence Scale for Children, Fourth Edition or who were receiving drug treatment were also excluded from this study. The number of children who participated in the camp was 68 ; 16 of these were excluded for such a reason as mentioned above. All participants were male students in the second, third or fourth grade in elementary school.

Participants with ADHD were assigned to one of three groups: pure ADHD ( $\mathrm{n}=22)$, ADHD with depressive symptoms $(\mathrm{n}=11)$, or ADHD with problematic internet use $(n=19)$. The Korean version of the Children's Depression Inventory (CDI) was used to assess depressive symptoms in children with ADHD. A CDI sum score of 20 was identified as the optimal screening cut-off score, for which the sensitivity was 0.83 and the specificity was 0.89 in Korean adolescents. ${ }^{29)}$ We also assessed participants using the Korean Internet Addiction Self-scale (K-scale), with total 
K-scale scores representing the severity of problematic internet use. Items are rated on a Likert scale $(1=$ never, $2=$ sometimes, $3=$ often, or $4=$ nearly always). The K-scale consists of six sub-factors: disturbance of adaptive functioning, addictive automatic thought, withdrawal, virtual interpersonal relationship, deviant behavior, and tolerance. The cut-off score was 3, which is the score generally used in clinical settings. ${ }^{30)}$ The validity and reliability of the K-scale was established for elementary school. The Cronbach's alpha score for the elementary school students was $0.887 .^{31)}$ Participants' guardians also completed the Korean parent and teacher ADHD Rating Scale (K-ARS), ${ }^{32)}$ the eight-item Disruptive Behavior Disorder Scale (DBDS) based on the Diagnostic and Statistical Manual of Mental Disorders 4th edition to assess ODD, ${ }^{33)}$ and the Korean version of the Learning Disability Evaluation Scale $(\mathrm{K}-\mathrm{LDES}){ }^{34)}$

\section{EEG Recording and Pre-processing}

The EEG recordings were performed using a SynAmps2 direct-current (DC) amplifier and a 10-20 layout 64-channel Quick-Cap electrode-placement system (Neuroscan Inc., Charlotte, NC, USA). The EEG data were digitally recorded from 19 gold cup electrodes placed according to the international 10-20 system. The impedances were maintained below $5 \mathrm{k} \Omega$, and the sampling rate was 1,000 Hz. We used the linked mastoid reference and two additional bipolar electrodes to measure horizontal and vertical eye movements. During the recording, each participant laid in a semi-darkened, electrically shielded, soundattenuated room. A resting EEG was recorded after three minutes with the participant's eyes closed.

We used Matlab 7.0.1 (Math Works, Natick, MA, USA) and the EEGLAB toolbox ${ }^{35)}$ to pre-process and analyze the EEG recordings. First, the EEG data were downsampled to $250 \mathrm{~Hz}$. Next, the EEG data were detrended and mean-subtracted to remove the DC component. A 1-Hz high-pass filter and a 60-Hz notch filter were applied to remove the eye and electrical noise. Next, independent component analysis (ICA) was performed to remove the well-defined sources of artifacts. ICA has been demonstrated to reliably isolate artifacts caused by eye and muscle movements and heart noise. ${ }^{36)}$ Finally, clinical psychiatrists and EEG experts visually inspected the corrected EEGs. For the analysis, we selected more than two minutes of artifact-free EEG readings from the three-minute recordings.

\section{Power-spectrum Analysis of the EEG Recordings}

Five frequency bands were defined for further analysis: delta (1-4 Hz), theta (4-8 Hz), alpha (8-12 Hz), beta (12-30 $\mathrm{Hz}$ ), and gamma $(30-50 \mathrm{~Hz})$. The spectral power of the EEG data was calculated via fast Fourier transformation using the "spectrogram.m" function of the signal processing toolbox in Matlab. Time windows of 1,000 ms were applied to the spectral analysis using an 800 -ms overlap and the Hamming window. Finally, the absolute powers were averaged over all of the time windows and frequency bands for further analysis. Additionally, the activities at 19 sites were divided into three regions by averaging within each region: frontal (FP1, FP2, F3, F4, F7, F8, and Fz), central (T3, T4, C3, C4, and Cz), and posterior (O1, O2, T5, T6, P3, P4, and Pz).

\section{Statistical Analysis}

An analysis of variance (ANOVA) test was used to test group differences in age and clinical variables. EEG power differences were analyzed using a three-group (pure ADHD vs. ADHD with depressive symptoms vs. ADHD with problematic internet use) repeated measures factorial ANOVA including the individual frequency bands of the regions (anterior vs. central vs. posterior) as the within-subjects factor. We also used post hoc tests to determine specific group differences. To follow up tests at individual electrodes, the homogeneity of slopes between the groups was first assessed with the Levene test. If slopes were found to be homogeneous, a second step was performed using an ANOVA test to compare the activity of each individual electrode between the three groups. When the assumption of sphericity was violated, the GreenHouseGeisser estimates were reported. Statistical significance was set at $p<0.05$. To control for false positives from multiple comparisons, we used the false discovery rate correction, in which the p-values were multiplied by the number of comparisons. ${ }^{37)}$ All data were analyzed using the PASW Statistics software, version 18.0 (IBM Co., Armonk, NY, USA).

\section{RESULTS}

\section{Demographic and Clinical Data}

No significant differences in age, K-ARS, Young's Internet Addiction Scale (IAS), K-LDES, or DBDS were observed between the three groups. Demographic and clinical variables are summarized in Table 1. 
Table 1. Age and clinical characteristics in study subjects

\begin{tabular}{|c|c|c|c|c|c|}
\hline & Pure ADHD $(n=22)$ & $\begin{array}{l}\text { ADHD with depressive } \\
\text { symptoms }(n=11)\end{array}$ & $\begin{array}{l}\text { ADHD with problematic } \\
\text { internet use }(n=19)\end{array}$ & $F / \chi^{2}$ & $p$ value \\
\hline Age & $8.45 \pm 1.71$ & $9.82 \pm 1.99$ & $9.32 \pm 1.92$ & 2.290 & 0.112 \\
\hline K-ARS & $28.05 \pm 9.12$ & $27.45 \pm 7.65$ & $31.58 \pm 10.37$ & 0.978 & 0.383 \\
\hline IAS & $15.27 \pm 13.77$ & $18.36 \pm 19.56$ & $20.21 \pm 20.89$ & 0.398 & 0.674 \\
\hline K-scale & $0.73 \pm 0.77$ & $3.18 \pm 3.31$ & $6.26 \pm 3.26$ & 24.411 & $<0.001^{*}$ \\
\hline K-LDES & $12.36 \pm 6.87$ & $16.18 \pm 8.24$ & $17.05 \pm 11.05$ & 1.569 & 0.219 \\
\hline DBDS & $8.50 \pm 4.54$ & $8.64 \pm 5.75$ & $9.53 \pm 6.35$ & 0.193 & 0.825 \\
\hline CDI & $11.09 \pm 4.89$ & $25.73 \pm 4.76$ & $7.00 \pm 5.30$ & 49.911 & $<0.001^{\dagger}$ \\
\hline
\end{tabular}

Data are given as the mean \pm standard deviation.

Analysis of variance (ANOVA) and post hoc was used.

ADHD, attention deficit/hyperactivity disorder; K-ARS, the Korean parent and teacher ADHD Rating Scale; IAS, Young's Internet Addiction Scale; K-scale, Korean version of the Internet Addiction Test; K-LDES, Korean version of Learning Disability Evaluation Scale; DBDS, Disruptive Behavior Disorder Scale according to the Diagnostic and Statistical Manual of Mental Disorders 4 th edition; CDI, Korean version of Children's Depression Inventory.

${ }^{\star} 1<2<3 ;{ }^{\dagger} 1=3<2$ (1, pure ADHD; 2, ADHD with depressive symptoms; 3 , ADHD with problematic internet use).

Pure ADHD

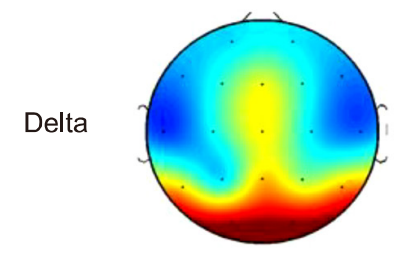

Theta

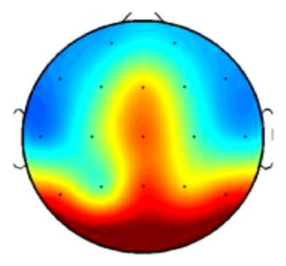

Alpha

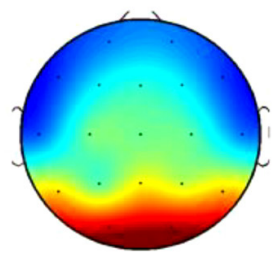

Beta
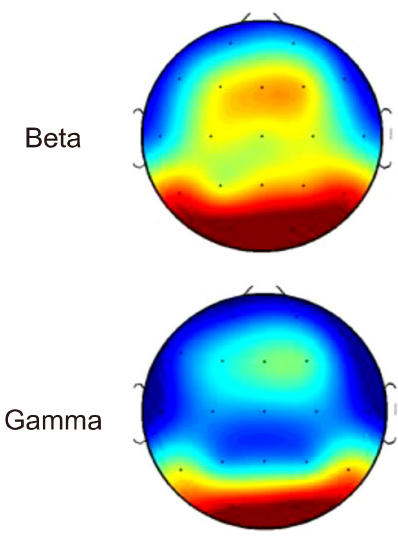

ADHD with depressive symptom
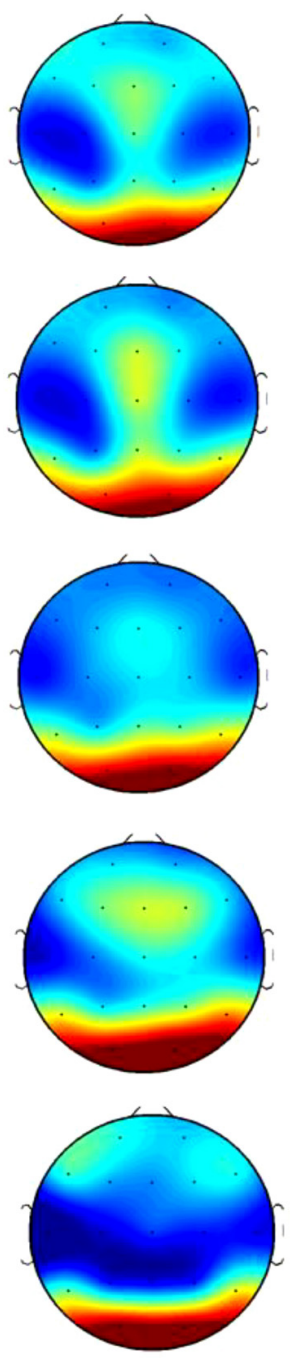

ADHD with

problematic internet use
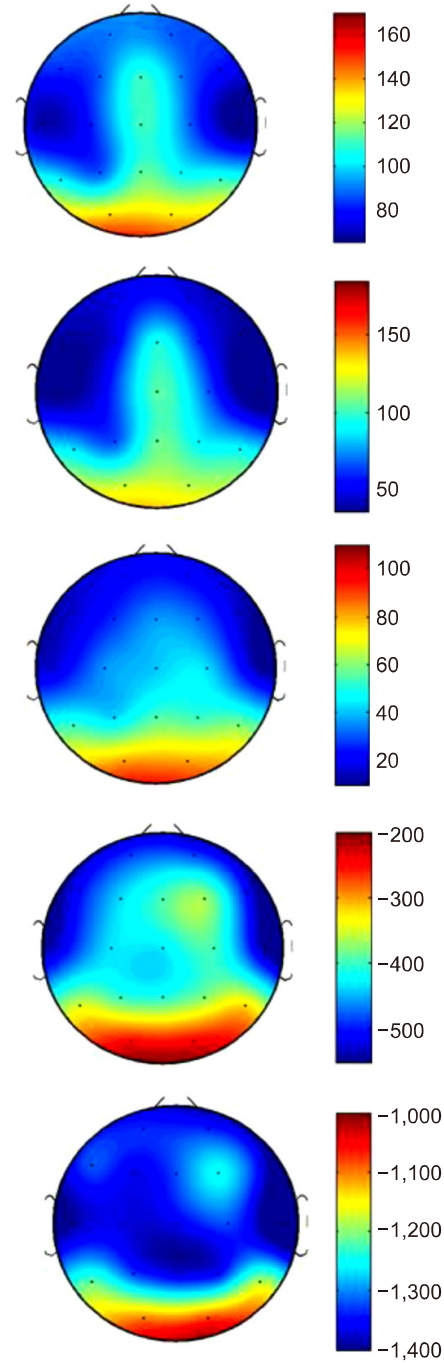

Fig. 1. Topographical maps of absolute power among groups. Scale shows $\mu \mathrm{V} 2$ for absolute power. Red color represents higher value; blue color represents lower value. The attention deficit/hyperactivity disorder (ADHD) with problematic internet use group demonstrates reduced absolute power in the theta band compared with the pure ADHD group. 


\section{QEEG Activity}

\section{Comparison between three groups: Repeated measures} ANOVA

Figure 1 shows the scalp topographies of the three groups in terms of the absolute power in each band. A significant main effect of the group was found for the absolute theta power (degree of freedom $[d f]=2, F=3.828$, $p=0.029$ ). After applying a post hoc test using the Bonferroni correction, this power was higher in the pure ADHD group than in the ADHD with problematic internet use in all regions, with the highest in the posterior region and the lowest in the anterior region (Fig. 2). We also found significant main effects for the region and the region by group interaction on absolute theta power $(d f=2, F=145.373, p$ $<0.001 ; d f=4, F=4.166, p=0.004$, respectively). Although both delta and alpha powers showed a significant region by group interaction, follow-up analyses using the Bonferroni correction revealed no significant effect of the group for delta or alpha power at any region (all $p>0.05$ ). Additionally, no significant main effects for the group or the region by group interaction on beta and gamma powers were observed (Table 2).

Comparison between three groups: ANOVA test of the individual electrodes

There was a significant main effect of the group for theta power. Follow-up comparisons analyzed the average EEG power of the individual electrodes that had sig-

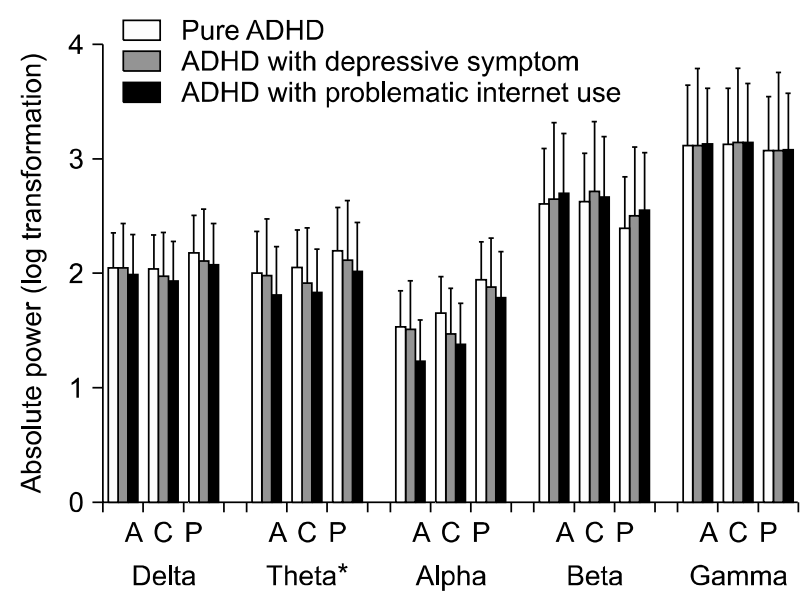

Fig. 2. Absolute electroencephalogram power in each band during the resting state condition. The data are reported as the mean \pm the standard error of the mean. ADHD, attention deficit/ hyperactivity disorder; A, anterior part; C, central part; P, posterior part.

*Pure ADHD > ADHD with problematic internet use (post hoc, $p$ $<0.05)$. nificant frequencies for the three groups. The absolute theta power was relatively high in the pure ADHD group at the central $(\mathrm{C} 3, \mathrm{~T} 4$, and $\mathrm{Cz})$ and posterior $(\mathrm{P} 3, \mathrm{O} 1, \mathrm{O} 2, \mathrm{~T} 5$, $\mathrm{T} 6$, and $\mathrm{Pz}$ ) regions. However, no group differences were observed for the theta power at the frontal region. The ADHD with depressive symptom group showed no significant differences in any region compared with the pure ADHD group or the ADHD with problematic internet use group (Table 3 ).

\section{DISCUSSION}

To the best of our knowledge, this is the first resting-state EEG study to investigate brain electrical activity in boys with ADHD according to comorbid psychiatric symptoms. We found electrophysiological differences between the children with ADHD depending on the presence of problematic internet use. The ADHD with problematic internet use group showed decreased absolute theta power at the central and posterior regions compared with the pure ADHD group. However, the ADHD with depressive symptom group had no significant impacts on QEEG activities in any region.

Contrary to the hypothesis, this study revealed that depressive symptoms in children with ADHD do not significantly influence the results of QEEG. Most existing EEG findings regarding depression report regional differ-

Table 2. Repeated measures ANOVAs of resting electroencephalogram frequency power among three groups

\begin{tabular}{|c|c|c|c|}
\hline \multirow{2}{*}{ Frequency band } & \multicolumn{3}{|c|}{ ANOVA } \\
\hline & $d f$ & $\mathrm{~F}$ & $p$ value \\
\hline \multicolumn{4}{|l|}{ Delta } \\
\hline Group & 2 & 2.999 & 0.059 \\
\hline Region & 2 & 155.034 & $<0.001^{*}$ \\
\hline Group×region & 4 & 3.747 & $0.007^{*}$ \\
\hline \multicolumn{4}{|l|}{ Theta } \\
\hline Group & 2 & 3.828 & $0.029^{*}$ \\
\hline Region & 2 & 145.373 & $<0.001^{*}$ \\
\hline Group×region & 4 & 4.166 & $0.004^{*}$ \\
\hline \multicolumn{4}{|l|}{ Alpha } \\
\hline Group & 2 & 1.879 & 0.164 \\
\hline Region & 2 & 357.001 & $<0.001^{*}$ \\
\hline Group×region & 4 & 2.665 & $0.037^{*}$ \\
\hline \multicolumn{4}{|l|}{ Beta } \\
\hline Group & 2 & 2.648 & 0.081 \\
\hline Region & 1.580 & 100.221 & $<0.001^{*}$ \\
\hline Group×region & 3.161 & 1.586 & 0.197 \\
\hline \multicolumn{4}{|l|}{ Gamma } \\
\hline Group & 2 & 0.761 & 0.473 \\
\hline Region & 1.712 & 45.264 & $<0.001^{*}$ \\
\hline Group ×region & 3.423 & 0.880 & 0.466 \\
\hline
\end{tabular}


Table 3. Comparison of absolute electroencephalogram power in the theta band among three groups

\begin{tabular}{|c|c|c|c|c|c|}
\hline & Pure ADHD (A) & $\begin{array}{c}\text { ADHD with depressive } \\
\text { symptom (B) }\end{array}$ & $\begin{array}{c}\text { ADHD with problematic } \\
\text { internet use (C) }\end{array}$ & $F / P$ & Post hoc \\
\hline Fpl & $89.39 \pm 12.02$ & $88.78 \pm 15.25$ & $62.75 \pm 15.34$ & $1.194 / 0.312$ & \\
\hline Fp2 & $91.97 \pm 11.59$ & $82.82 \pm 18.14$ & $60.17 \pm 15.38$ & $1.447 / 0.245$ & \\
\hline F3 & $106.46 \pm 11.27$ & $97.12 \pm 15.32$ & $61.14 \pm 17.51$ & $0.862 / 0.067$ & \\
\hline F4 & $105.79 \pm 11.60$ & $98.74 \pm 12.90$ & $68.84 \pm 16.42$ & $2.099 / 0.133$ & \\
\hline F7 & $84.47 \pm 10.76$ & $86.02 \pm 10.97$ & $53.85 \pm 13.07$ & $2.291 / 0.112$ & \\
\hline F8 & $84.85 \pm 11.24$ & $85.44 \pm 16.10$ & $51.47 \pm 13.55$ & $2.225 / 0.119$ & \\
\hline $\mathrm{Fz}$ & $138.61 \pm 8.60$ & $121.43 \pm 14.87$ & $101.08 \pm 15.02$ & $2.593 / 0.085$ & \\
\hline T3 & $81.87 \pm 11.57$ & $61.90 \pm 12.59$ & $47.28 \pm 12.96$ & $2.211 / 0.120$ & \\
\hline T4 & $90.29 \pm 11.15$ & $69.15 \pm 14.64$ & $36.27 \pm 13.86$ & $4.992 / 0.011^{*}$ & $A>C$ \\
\hline C3 & $111.57 \pm 8.42$ & $98.74 \pm 12.90$ & $68.84 \pm 16.42$ & $4.934 / 0.011^{*}$ & $A>C$ \\
\hline C4 & $109.31 \pm 9.24$ & $77.97 \pm 13.36$ & $75.77 \pm 12.03$ & $3.077 / 0.055$ & \\
\hline $\mathrm{Cz}$ & $151.14 \pm 7.67$ & $122.92 \pm 13.72$ & $109.18 \pm 12.68$ & $4.433 / 0.017^{*}$ & $A>C$ \\
\hline O1 & $185.05 \pm 14.02$ & $157.37 \pm 16.77$ & $124.74 \pm 15.38$ & $4.485 / 0.016^{*}$ & $A>C$ \\
\hline О2 & $184.06 \pm 12.57$ & $170.69 \pm 19.37$ & $121.85 \pm 15.36$ & $5.219 / 0.009^{*}$ & $A>C$ \\
\hline T5 & $152.08 \pm 14.01$ & $112.77 \pm 18.52$ & $95.43 \pm 14.31$ & $4.223 / 0.020^{*}$ & $A>C$ \\
\hline T6 & $160.17 \pm 15.03$ & $126.18 \pm 16.79$ & $99.17 \pm 16.68$ & $4.062 / 0.023^{*}$ & $A>C$ \\
\hline P3 & $136.84 \pm 9.64$ & $103.46 \pm 15.32$ & $93.03 \pm 14.52$ & $3.659 / 0.033^{*}$ & $A>C$ \\
\hline P4 & $135.83 \pm 8.82$ & $102.36 \pm 13.52$ & $96.65 \pm 15.99$ & $3.019 / 0.058$ & \\
\hline $\mathrm{Pz}$ & $157.03 \pm 8.49$ & $119.33 \pm 18.95$ & $111.02 \pm 16.20$ & $3.602 / 0.035^{\star}$ & $A>C$ \\
\hline
\end{tabular}

ADHD, attention deficit/hyperactivity disorder.

Mean absolute power in $\mu \mathrm{V} 2$ (standard error).

Analysis of variance with Bonferroni post hoc test; * $p \leq 0.05$.

ences in alpha power. ${ }^{38)}$ Both alpha power deviation on the power spectrum and higher alpha power synchrony and connectivity are identified as distinct findings in patients with depression. ${ }^{39,40)}$ Therefore, alpha power was expected to appear differently in the group of children with ADHD and depressive symptoms. However, no significant differences were found. One previous study reported that comorbid depression in children with ADHD affects the theta-to-beta ratio in ADHD; ${ }^{12)}$ however, in this study, theta and beta power did not show a significant difference. These results can be explained by two factors. First, the statistical power of this study may not be sufficient because the sample size of the group of boys with ADHD and depressive symptoms was smaller than those of the other two groups. Although an existing study reported that the theta-to-beta ratio tends to be higher when ADHD and ODD coexist, its statistical significance was not evident because of the modest sample size $(n=25) .{ }^{14}$ Second, the depressive symptoms in this study's participants were not sufficiently severe for a diagnosis of major depression, although several measures confirmed that they do exist. Notably, the participants diagnosed with a mood disorder based on DISC-IV, which was an initial assessment, and who obviously have functional impairment because of a mood disorder were excluded from this study. In terms of the severity of the depressive symptoms, a substantial gap was observed between the comorbid depressive symptoms defined in this study and those defined in previous studies. Accordingly, depressive symptoms did not significantly influence EEG in this study.

In boys with $\mathrm{ADHD}$, problematic internet use has a significant influence on theta power. A few studies have addressed the effects of psychiatric comorbidity in ADHD on EEG. One such study was conducted with children with ADHD comorbid with ODD or CD to investigate the effects of the comorbidity on EEG. Although that study did not detect any significant effect, it revealed that the group with ADHD symptoms showed only noticeable focal theta abnormalities. ${ }^{14)}$ A study investigating alpha and theta reactivity related to open eyes during the resting state also reported that the pure ADHD group, which includes subjects without any comorbid disorders, such as ODD, shows more theta deviance. ${ }^{28)}$ Similar to these previous studies, this study also found that the pure ADHD group displayed significantly higher theta power deviance than the problematic internet use group. However, these results should be interpreted carefully. Previous studies reported that increased theta power is related to poor performance in attention-demanding cognitive tasks. ${ }^{41)}$ However, it is inappropriate to conclude that decreased theta power in the problematic internet use group indicates better cognitive function in the problematic internet use group. According to a recent study, although increased theta power is a distinct neurophysiological finding in ADHD, relationships between resting-state brain oscillation and cognitive function are not consistent. ${ }^{42)}$ Additionally, sim- 
ilar to the depressive symptoms mentioned previously, the symptoms of the children in the problematic internet use group, which were assessed based on the K-scale, do not necessarily indicate that these children have been diagnosed with internet addiction or behavioral addiction. For an accurate diagnosis, whether the patients have experienced the typical components of addiction must be assessed (i.e., tolerance, withdrawal, preoccupation with playing online games, repeated unsuccessful attempts to reduce or stop online gaming, negatively influenced mood when attempting to reduce online gaming, and neglecting important relationships or activities because of online games) ${ }^{43)}$ Therefore, further studies should assess differences in cognitive function and changes in EEG based on comorbid symptoms, and the results of this study must be interpreted to determine whether problematic internet use by children with ADHD influences their EEG theta power.

There are several limitations to this study. First, as previously mentioned, psychiatric symptoms, such as depressive symptoms or problematic internet use in boys with ADHD, do not indicate a disorder but instead represent specific symptoms. Therefore, careful consideration must be used when applying this study's results to cases in which children with ADHD have comorbid depressive disorder or internet addiction. However, these symptoms require attention because subsyndromal symptoms that do not meet the diagnostic criteria are associated with a high prevalence rate and functional impairment across a broad area. ${ }^{44)}$ Second, the size of the depressive symptom group in this study ( $\mathrm{n}=11)$ was smaller than those of the other groups, raising questions regarding the statistical power of the analytical findings. Third, significant differences were observed in the CDI and K-scale scores between the three groups, which may have had confounding effects. To control for the effects of CDI and K-scale scores on the QEEG results, we performed a reanalysis using $\mathrm{CDI}$ and $\mathrm{K}$-scale scores as covariates, and the significant differences in theta power between the groups persisted.

This study also has two strengths. First, although an age-matched sample was not used, similar-aged children participated. Therefore, this study could exclude the effects of age. In a comparison analyses, the EEG abnormalities associated with ADHD differ depending on age. At an individual level, the results of EEG also tend to vary and show relatively sharp changes as time passes. ${ }^{26)}$ Second, this study was able to exclude the effects of drugs because none of the participants were taking medications. Stimulants, the major medication for ADHD, have been studied to investigate how they influence brain wave ac- tivity, and the theta power has been reported to be decreased or increased. Previous studies clearly show that taking medication affects the results of EEG. ${ }^{45,46)}$

The present study investigated the differences in resting-state QEEG patterns in boys with ADHD with or without comorbid psychiatric symptoms. The ADHD with depressive symptom group showed no significant differences compared with the other groups. This finding suggests that the subsyndromal symptoms of depression do not significantly influence QEEG results in ADHD. The ADHD with problematic internet use group showed significant EEG deviation in theta frequency. These differences may be associated with the pathophysiologies of internet addiction and behavioral addiction. Because no previous studies have reported this association, further replicative studies are required to establish the association. This research will contribute to a better understanding of brainbased electrophysiological changes in children with ADHD in accordance with comorbid psychiatric symptoms.

\section{REFERENCES}

1. Biederman J, Faraone SV. Attention deficit hyperactivity disorder: a worldwide concern. J Nerv Ment Dis 2004;192: 453-454.

2. American Psychiatric Association. Diagnostic and statistical manual of mental disorders: DSM-5. Arlington:American Psychiatric Association;2013.

3. Pastor PN, Reuben CA. Diagnosed attention deficit hyperactivity disorder and learning disability: United States, 2004-2006. Vital Health Stat 10 2008;(237):1-14.

4. Bowen R, Chavira DA, Bailey K, Stein MT, Stein MB. Nature of anxiety comorbid with attention deficit hyperactivity disorder in children from a pediatric primary care setting. Psychiatry Res 2008;157:201-209.

5. Ostrander R, Crystal DS, August G. Attention deficithyperactivity disorder, depression, and self-and otherassessments of social competence: a developmental study. $J$ Abnorm Child Psychol 2006;34:773-787.

6. Strine TW, Lesesne CA, Okoro CA, McGuire LC, Chapman DP, Balluz LS, et al. Emotional and behavioral difficulties and impairments in everyday functioning among children with a history of attention-deficit/hyperactivity disorder. Prev Chronic Dis 2006;3:A52.

7. Biederman J, Faraone S, Milberger S, Guite J, Mick E, Chen $\mathrm{L}$, et al. A prospective 4-year follow-up study of attentiondeficit hyperactivity and related disorders. Arch Gen Psychiatry 1996;53:437-446.

8. Spencer TJ, Biederman J, Mick E. Attention-deficit/ hyperactivity disorder: diagnosis, lifespan, comorbidities, and neurobiology. J Pediatr Psychol 2007;32:631-642.

9. Kim S, Kim MS. Deficits in verbal working memory among college students with attention-deficit/hyperactivity disorder traits: an event-related potential study. Clin Psychopharmacol Neurosci 2016;14:64-73.

10. Sadock BJ, Sadock VA. Kaplan and Sadock's synopsis of psychiatry: behavioral sciences/clinical psychiatry. 10th ed. Philadelphia:Lippincott Williams \& Wilkins;2011. 
11. Jensen PS, Hinshaw SP, Kraemer HC, Lenora N, Newcorn $\mathrm{JH}$, Abikoff $\mathrm{HB}$, et al. ADHD comorbidity findings from the MTA study: comparing comorbid subgroups. J Am Acad Child Adolesc Psychiatry 2001;40:147-158.

12. Loo SK, Cho A, Hale TS, McGough J, McCracken J, Smalley SL. Characterization of the theta to beta ratio in ADHD identifying potential sources of heterogeneity. J Atten Disord 2013;17:384-392.

13. Yoo HJ, Cho SC, Ha J, Yune SK, Kim SJ, Hwang J, et al. Attention deficit hyperactivity symptoms and internet addiction. Psychiatry Clin Neurosci 2004;58:487-494.

14. Clarke AR, Barry RJ, McCarthy R, Selikowitz M. Children with attention-deficit/hyperactivity disorder and comorbid oppositional defiant disorder: an EEG analysis. Psychiatry Res 2002;111:181-190.

15. Spencer T, Biederman J, Wilens T. Attention-deficit/ hyperactivity disorder and comorbidity. Pediatr Clin North Am 1999;46:915-927, vii.

16. Daviss WB. A review of co-morbid depression in pediatric ADHD: etiologies, phenomenology, and treatment. J Child Adolesc Psychopharmacol 2008;18:565-571.

17. Chan PA, Rabinowitz T. A cross-sectional analysis of video games and attention deficit hyperactivity disorder symptoms in adolescents. Ann Gen Psychiatry 2006;5:16.

18. Yen JY, Yen $\mathrm{CF}$, Chen $\mathrm{CS}$, Tang $\mathrm{TC}$, Ko $\mathrm{CH}$. The association between adult ADHD symptoms and internet addiction among college students: the gender difference. Cyberpsychol Behav 2009;12:187-191.

19. Petry NM, O'Brien CP. Internet gaming disorder and the DSM-5. Addiction 2013;108:1186-1187.

20. Corsi-Cabrera M, Galindo-Vilchis L, del-Río-Portilla Y, Arce C, Ramos-Loyo J. Within-subject reliability and inter-session stability of EEG power and coherent activity in women evaluated monthly over nine months. Clin Neurophysiol 2007;118:9-21.

21. González-Castro P, Rodríguez C, López Á, Cueli M, Álvarez L. Attention deficit hyperactivity disorder, differential diagnosis with blood oxygenation, beta/theta ratio, and attention measures. Int J Clin Health Psycol 2013;13: 101-109.

22. Shi T, Li X, Song J, Zhao N, Sun C, Xia W, et al. EEG characteristics and visual cognitive function of children with attention deficit hyperactivity disorder (ADHD). Brain Dev 2012;34:806-811.

23. Clarke AR, Barry RJ, Dupuy FE, Heckel LD, McCarthy R, Selikowitz $\mathrm{M}$, et al. Behavioural differences between EEGdefined subgroups of children with attention-deficit/ hyperactivity disorder. Clin Neurophysiol 2011;122:1333-1341.

24. Dupuy FE, Clarke AR, Barry RJ, McCarthy R, Selikowitz M. Girls with attention-deficit/hyperactivity disorder: EEG differences between DSM-IV types. Clin EEG Neurosci 2011:42:1-5.

25. Clarke AR, Barry RJ, McCarthy R, Selikowitz M. Age and sex effects in the EEG: differences in two subtypes of attention-deficit/hyperactivity disorder. Clin Neurophysiol 2001;112:815-826.

26. Liechti MD, Valko L, Müller UC, Döhnert M, Drechsler R, Steinhausen HC, et al. Diagnostic value of resting electroencephalogram in attention-deficit/hyperactivity disorder across the lifespan. Brain Topogr 2013;26:135-151.

27. Barry RJ, Clarke AR, Johnstone SJ, McCarthy R, Selikowitz M. Electroencephalogram theta/beta ratio and arousal in attention-deficit/hyperactivity disorder: evidence of independent processes. Biol Psychiatry 2009;66:398-401.

28. Buyck I, Wiersema JR. State-related electroencephalo- graphic deviances in attention deficit hyperactivity disorder. Res Dev Disabil 2014;35:3217-3225.

29. Bang YR, Park JH, Kim SH. Cut-off scores of the children's depression inventory for screening and rating severity in Korean adolescents. Psychiatry Investig 2015;12:23-28.

30. Koh YS. Development and application of $K$-Scale as diagnostic scale for Korean Internet addiction. In: International Symposium on the Counseling and Treatment of Youth Internet Addiction 2007. Seoul:National Youth Commission;2007.

31. Kim BG, Kim DI, Kim DM, Ko YS, Eom NR, Lee EA, et al. The follow up study of internet addiction proneness scale. Seoul:National Information Society Agency;2008.

32. So YK, Noh JS, Kim YS, Ko SG, Koh YJ. The reliability and validity of Korean parent and teacher ADHD rating scale. J Korean Neuropsychiatr Assoc 2002;41:283-289.

33. Ise E, Görtz-Dorten A, Döpfner M. Reliability and validity of teacher-rated symptoms of oppositional defiant disorder and conduct disorder in a clinical sample. Psychopathology 2014:47:312-318

34. Shin MS, Hong KE, Kim ZS, Cho SC. A standardization study of the Korean version of learning disability evaluation scale. J Korean Neuropsychiatr Assoc 1998;37:1233-1245.

35. Delorme A, Makeig S. EEGLAB: an open source toolbox for analysis of single-trial EEG dynamics including independent component analysis. $J$ Neurosci Methods 2004;134:9-21.

36. Jung TP, Makeig S, Humphries C, Lee TW, Mckeown MJ, Iragui $\mathrm{V}$, et al. Removing electroencephalographic artifacts by blind source separation. Psychophysiology 2000;37:163-178.

37. Benjamini Y, Hochberg Y. Controlling the false discovery rate: a practical and powerful approach to multiple testing. $J$ R Statist Soc B 1995;57:289-300.

38. Thibodeau R, Jorgensen RS, Kim S. Depression, anxiety, and resting frontal EEG asymmetry: a meta-analytic review. J Abnorm Psychol 2006;115:715-729.

39. Feng X, Forbes EE, Kovacs M, George CJ, Lopez-Duran NL, Fox NA, et al. Children's depressive symptoms in relation to EEG frontal asymmetry and maternal depression. J Abnorm Child Psychol 2012;40:265-276.

40. Leuchter AF, Cook IA, Hunter AM, Cai C, Horvath S. Resting-state quantitative electroencephalography reveals increased neurophysiologic connectivity in depression. PLoS One 2012;7:e32508.

41. Hermens DF, Soei EX, Clarke SD, Kohn MR, Gordon E, Williams LM. Resting EEG theta activity predicts cognitive performance in attention-deficit hyperactivity disorder. Pediatr Neurol 2005;32:248-256.

42. Lansbergen MM, Arns $M$, van Dongen-Boomsma $M$, Spronk D, Buitelaar JK. The increase in theta/beta ratio on resting-state EEG in boys with attention-deficit/hyperactivity disorder is mediated by slow alpha peak frequency. Prog Neuropsychopharmacol Biol Psychiatry 2011;35:47-52.

43. Flisher C. Getting plugged in: an overview of internet addiction. J Paediatr Child Health 2010;46:557-559.

44. Pietrzak R, Kinley J, Afifi T, Enns MW, Fawcett J, Sareen J. Subsyndromal depression in the United States: prevalence, course, and risk for incident psychiatric outcomes. Psychol Med 2013;43:1401-1414.

45. Clarke AR, Barry RJ, McCarthy R, Selikowitz M, Johnstone SJ. Effects of stimulant medications on the EEG of girls with attention-deficit/hyperactivity disorder. Clin Neurophysiol 2007; 118:2700-2708

46. Wienbruch C, Paul I, Bauer S, Kivelitz H. The influence of methylphenidate on the power spectrum of $A D H D$ children-an MEG study. BMC Psychiatry 2005;5:29. 